\title{
Selvmordsrisiko hos personer med tidligere psykiatrisk sykehusinnleggelse
}

\author{
Ved Ping Qin
}

\section{Forebygging av selvmord hos mennesker med psykiske lidelser er et prioritert område innen folkehelse- arbeidet.}

Funn fra både kliniske studier og befolkningsstudier viser at pasienter med ulike psykiske lidelser har en forhøyet selvmordsrate (Harris \& Barraclough, 1997). Det å ha eller ha hatt en psykisk lidelse er den sterkeste risikofaktoren for selvmord i den generelle befolkning (Mortensen, Agerbo, Erikson, Qin, \& Westergaard-Nielsen, 2000; Rihmer, 2007; Saha, Chant, \& McGrath, 2007). Men betydningen av psykiatrisk sykdom for selvmordsrisikoen varierer avhengig av viktige faktorer som den spesifikke diagnose, graden av sykdom og pasientens kjønn og alder. Systematiske studier av disse ulike faktorene kan gi oss verdifull innsikt når vi skal legge strategier for å redusere selvmordsdødeligheten i denne høyrisikogruppen av befolkningen.

Fordi Danmark har et vel fungerende befolkningsdekkende registreringssystem, har vi vært i den heldige posisjon at vi har kunnet framskaffe data fra Danmarks ulike medisinske og administrative registre til en serie selvmordsforskningsprosjekter. I denne artikkelen oppsummeres resultatene av våre studier av selvmordsrisiko i relasjon til det å ha en historie med sykehusinnleggelser for psykiske lidelser. Hovedformålet er å gi en oversikt over hvordan selvmordsrisiko er assosiert med faktorer tilknyttet innleggelse i psykisk helsevern, hvordan risikoen varierer i forhold til kjønn og alder, og risikoutviklingen over tid.

\section{Selvmordsrisiko i forhold til syke- husinnleggelse for psykiatrisk sykdom}

I våre studier, som inkluderte 21169 selvmord i årene 1981 til 1997 (Qin, Agerbo, \& Mortensen, 2003; Qin \& Nordentoft, 2005), fant vi at $37 \%$ av mennene og $57 \%$ av kvinnene som hadde tatt sitt eget liv tidligere hadde vært innlagt i psykiatrisk sykehusavdeling. Sammenlignet med personer av samme kjønn og alder som ikke hadde vært psykiatrisk sykehusinnlagt var risikoen for selvmord 14,1 ganger høyere for menn og 22,7 ganger høyere for kvinner som hadde vært psykiatrisk sykehusinnlagt. Da vi korrigerte for individuell sivilstand, årlig inntekt og bosted, ble den assosierte risikoen redusert svakt til henholdsvis 10,4 ganger for menn og 19,8 ganger for kvinner. Alt i alt var det en signifikant forskjell mellom kjønnene på effekten av å ha en historie med sykehusinnleggelser i psykisk helsevern $(\mathrm{p}<0.001)$; den $\varnothing$ kte risikoen for selvmord var signifikant større hos kvinner enn hos menn.

Samtidig viste vår undersøkelse at det er stor variasjon i selvmordsrisiko avhengig av tiden siden siste innleggelse eller utskrivning, hoveddiagnose, lengden på behandlingen i sykehus, så vel som antallet innleggelser i psykisk helsevern (Qin et al., 2005)(fig. 1). For både menn og kvinner var det to tydelige topper av selvmordsrisiko rundt innleggelsen. Risikoen var ekstremt høy i den f $\varnothing$ rste uken etter innleggelse og framfor alt i den første uken etter utskrivning. Deretter minket risikoen gradvis om man var innlagt lenger eller ettersom tiden gikk etter utskrivning. Sammenliknet med diagnoser innen spekteret av schizofrene lidelser, var selvmordsrisikoen noe høyere for stemningslidelser - både for menn og kvinner - og for rusmisbruk hos kvinner.
Videre var selvmordsrisikoen signifikant høyere for pasienter med kortere innleggelser i sykehus, og risikoen $\varnothing$ kte med $\varnothing$ kende antall innleggelser i psykiatrisk sykehus (Qin et al., 2005).

Da vi inkluderte disse variablene i analysen og samtidig justerte for sivilstatus, inntekt og bosted, ble den $\varnothing$ kte risikoen knyttet til studievariablene ganske redusert. Likevel vedble de to tydelige toppene av selvmordsrisiko, og risikoen for selvmord i uken etter innleggelse var 59,8 ganger forhøyet hos menn og 81,6 ganger hos kvinner, mens risikoen for selvmord i uken etter utskrivning var forh $\varnothing$ yet 102,0 ganger hos menn og 246,0 ganger hos kvinner. Samtidig var risikoen forbundet med stemningslidelser i forhold til lidelser i schizofrenispekteret omtrent 1,9 ganger høyere hos menn og 1,6 ganger høyere hos kvinner, og effekten av rusmisbrukslidelser hos kvinner gav også 1,6 ganger høyere selvmordsrisiko hos kvinner. Etter justeringen $\varnothing \mathrm{kte}$ risikoen assosiert med korte sykehusinnleggelser litt, mens den vesentlige risikoen assosiert med gjentatte innleggelser i psykisk helsevern forble klart signifikant kun for kvinner.
Figur 1. Justert risikoratio for selvmord sett i forhold til tidspunktet for siste innleggelse i psykiatrisk sykehus

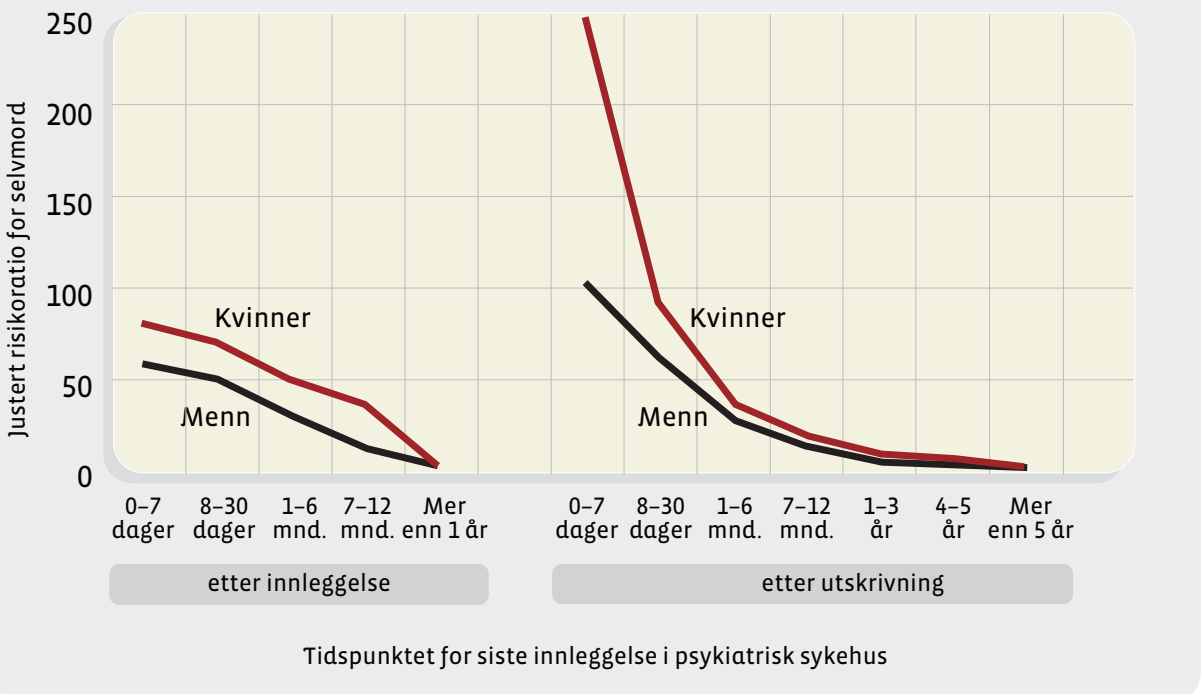


Da vi studerte diagnostiske variabler nærmere, viste vår studie at størrelsen på risikoen for selvmord på tvers av de ulike fasene av innleggelse og behandling varierte signifikant i forhold til diagnose hos både menn og kvinner (Qin et al., 2005). Stemningslidelser $\varnothing$ kte selvmordsrisikoen til det høyeste nivå på tvers av alle faser av innleggelse med en ekstremt høy risiko den første uken etter utskrivning; 1976,5 ganger for kvinner og 218,8 for menn. Ved både stemningslidelser og lidelser i schizofrenispekteret $\varnothing \mathrm{kte}$ selvmordsrisikoen straks etter innleggelse og utskrivning, hvoretter risikoen sank raskt etter behandling og bedring. For rusmisbrukslidelser $\varnothing$ kte imidlertid risikoen mindre like etter innleggelse og utskrivning, men sank til gjengjeld sakte etter behandling og bedring.

Vi omformet distribusjon og risikoratio til populasjonsattribuerbar risiko (PAR) - et mål som indikerer hvor mange selvmord som kunne vært forebygget om selvmordsrisikoen knyttet til eksponeringen for risikofaktoren ble redusert til nivået for referansegruppen. Våre funn indikerer at risikoen assosiert med å ha vært innlagt i psykisk helsevern utgjorde $33,2 \%$ av risikoen for menn og 53,2 \% for kvinner, og halvparten av dette var assosiert med psykiatrisk innleggelse de siste 6 månedene. Stemningslidelser synes å bidra med den st $\varnothing$ rste andelen av PAR; $8,5 \%$ hos menn og 18,9\% hos kvinner (Qin et al., 2005).

Disse sistnevnte funnene indikerer at alvorsgraden av en psykisk lidelse spiller en viktig rolle for risikoen for selvmord, særlig i akutte sykdomsperioder. Det kan være flere grunner til at risikoen for selvmord er høy selv når pasienten er i ferd med å bli friskere eller kun er kortvarig innlagt. Blant annet kan det være at tilfriskningen er ufullstendig og at den psykiske tilstanden så forverrer seg. Det kan være at en brå avslutning av behandlingen kan øke sårbarheten, at utskrivning gjør at pasienten på nytt blir utsatt for belastningene som lå forut for innleggelsen, og at midlene til selvmord er lettere tilgjengelige utenfor sykehus. Pasienten kan frykte tilværelsen utenfor sykehuset fordi bevisstheten om å ha en psykisk lidelse kan ha en negativ virkning på pasientens selvfølelse og gi frykt for å bli stigmatisert. Om forklaringene på disse funnene er riktige, peker dette i retning av at det er viktig å fortsette intensiv klinisk behandling og omsorg selv etter at pasienten klinisk sett er frisk, for å redusere risikoen for selvmord hos pasienter med psykiske lidelser. Våre funn bør også føre til at man systematisk evaluerer selvmordsrisiko hos pasienter før utskrivning. Videre oppfølging av pasienten, og støtte til familien, fra psykiatrisk poliklinikk må igangsettes umiddelbart etter utskrivning fra sykehus. Spesielt er det viktig å gjøre en innsats for å korte ned tiden mellom utskrivning fra sykehus og iverksettelse av ettervern.

Vi har også beregnet populasjonsattribuerbar risiko i forhold til diagnose og tid siden innleggelse. For eksempel fant vi at 2,1\% av menns og 3,8\% av kvinners populasjonsattribuerbare risiko for selvmord ble utgjort av selvmord blant pasienter i løpet av den første uken etter utskrivning. Dette betyr at opp til 2,1\% av menns og 3,8 \% av kvinners selvmord kan forebygges gjennom en betydelig innsats for å gi intensive behandling og pleie til pasienter den første uken etter utskrivning. Selv om det lyder urealistisk å skulle forhindre alle disse selvmordene, antyder våre estimater at det kan være en effektiv bruk av midler å fors $\varnothing$ ke å forebygge selvmord i denne korte perioden.

\section{Utvikling av selvmordsrisiko i forhold til endringer i psykisk helsevern}

Selvmordsraten i Danmark har sunket uavbrutt i løpet av de siste 20 år. Raten var på 31,6 selvmord per 100000 innbyggere i 1980, og var redusert til 15,4 selvmord per 100000 innbyggere i 1997, en reduksjon av selvmordsraten på $51 \%$ i denne 18-årsperioden. Mange faktorer som er vist å være relevante eller å bidra til psykiske lidelser eller selvmord, er endret i løpet av de siste 20 årene. For eksempel er folks levestandard og livskvalitet i noen grad blitt bedre parallelt med den sosio $\varnothing$ konomiske og teknologiske utvikling som har skjedd. Det er iverksatt begrensninger i tilgangen til enkelte selvmordsmidler (Sundhedsstyrelsen, 1998). Omorganiseringen av psykisk helsevern har gitt en markert nedgang i antallet sykehussenger, men også en vesentlig $\varnothing$ kning i kommunale omsorgsboliger for psykisk syke (Socialministeriet og Sundhedsministeriet, 2002). Det er utviklet mer effektive medikamenter mot psykiske lidelser. Disse endringene har påvirket personer med psykiske lidelser på en annen måte enn personer uten psykiske lidelser. Vi har derfor unders $\varnothing$ kt endringene i selvmordsrate fra 1981 til 1997 blant pasienter som hadde hatt sykehusinnleggelser for psykiske lidelser sammenlignet med den generelle befolkning (Qin et al., 2006).

Vi fant at i perioden 1981 til 1997, mens selvmordsraten i Danmark sank kontinuerlig, skjedde reduksjonen i selvmordsraten generelt raskere blant individer som hadde vært sykehusinnlagt for psykiske lidelser enn blant individer som ikke hadde vært innlagt. Men denne betydelige reduksjonen består hovedsakelig av en raskere reduksjon av raten blant pasienter som var utskrevet fra psykiatrisk sykehus mer enn ett år tidligere. Blant dem som var utskrevet for mindre enn et år siden, var reduksjonen av selvmordsraten lik reduksjonen for befolkningen for $\varnothing v$ vig. Blant pasienter som var innlagt for behandling, skjedde reduksjonen saktere enn for den generelle befolkning. Disse trendene gjaldt begge kjønn og alle diagnostiske grupper. Den videre analyse inndelt etter alder indikerte at den raskere reduksjonen i selvmordsraten blant individer som hadde vært sykehusinnlagt for psykiske lidelser var til stede for alle aldersgrupper, men den var tydeligere for middelaldrende og eldre pasienter. Den mer langsomme reduksjonen i selvmordsraten blant innlagte pasienter var stort sett begrenset til eldre pasienter (Qin et al., 2006).

Denne raskere reduksjonen i selvmordsraten blant pasienter med psykiske lidelser i Danmark har skjedd samtidig med viktige endringer i tjenestetilbudet i det psykisk helsevern. Antallet sengeplasser i psykiatriske sykehus ble redusert med 60,5 \% fra 1980 (2,0 senger per 1000 innbyggere) til 1997 (0,79 senger per 1000 innbyggere) (Socialministeriet og Sundhedsministeriet, 2002). På den annen side har det vært en kontinuerlig $\varnothing$ kning i 
antallet bemannede omsorgsboliger i kommunene der pasienter som nylig er utskrevet eller er kroniske pasienter, kan få ettervern og behandling. Samtidig er også antallet personer ansatt i psykisk helsevern $\varnothing \mathrm{kt}$. Antallet ansatte i kommunale sentre for psykisk helsevern ble doblet mellom 1993 og 1997, og antallet ansatte i psykiatriske avdelinger ved sykehusene $\varnothing \mathrm{kte}$ med $30 \%$ (Socialministeriet og Sundhedsministeriet, 2002). Ansatte i psykisk helsevern kan nå også få i oppgave å gi hjemmetjenester for alvorlig psykisk syke (Socialministeriet og Sundhedsministeriet, 2002). Behandlingen av psykisk syke og den sosiale st $\varnothing$ tten til deres familier er altså blitt bedre i løpet av den perioden vi har studert. Dette gir mulighet for en tettere oppfølging utenfor sykehus, og for tettere observasjon og st $\varnothing$ tte under sykehusopphold.

Våre funn angående endringer i selvmordsraten blant pasienter som har vært sykehusinnlagt for psykiske lidelser, synes å samsvare med endringene i tjenestene i psykisk helsevern i Danmark. For eksempel kan reduksjonen av psykiatriske sengeplasser gjøre at det velges ut mer alvorlig syke pasienter for behandling i sykehus, og at det er en tendens til kortere innleggelser. Dette kan antagelig i stor grad forklare den mer langsomme reduksjonen i selvmordsraten blant pasienter som er innlagt, og spesielt blant de høyere aldersgruppene. Samtidig kan den tettere oppfølgingen og st $\varnothing$ tten fra tjenestene i det kommunale psykiske helsevern ha vært et effektivt supplement til sykehusbehandling som de polikliniske pasientene har nytt godt av. Dette kan ha gjort at disse pasientene hadde en like rask reduksjon i selvmordsraten som den generelle befolkning, og til og med en raskere reduksjon blant pasientene som ble utskrevet mer enn et år tidligere.

Vi tror også at forbedringer i behandlingen av både innlagte pasienter og polikliniske pasienter har bidratt til våre funn. For eksempel kan det være at den nye generasjonen antidepressive medisiner, slik som selektive serotonin-absorpsjonshemmere (SSRI-preparater), i stadig større grad blir brukt i stedet for de klassiske trisykliske antidepressivene. I Danmark har forbruket at SSRI-preparater $\varnothing \mathrm{kt}$ fra null (fordi de ikke var oppfunnet enda) døgndoser per 1000 innbyggere i 1981 til 17,1 i 1997 og til 31,4 døgndoser per 1000 innbyggere i 2002 (Lægemiddelstyrelsen, 1999, 2003). Selv om det er blitt hevdet at $\varnothing \mathrm{kt}$ forbruk av SSRIpreparater i en befolkning kan redusere selvmordsraten (Gunnell, Saperia, \& Ashby, 2005; Isacsson, Holmgren, \& Ahlner, 2005), mener vi effekten, om den finnes, først og fremst vil være avgrenset til pasienter med psykiske lidelser, og spesielt til pasienter i en klinisk fase med fortsatt behandling eller vedlikeholdsbehandling (Bramness, Walby, \& Tverdal, 2007).

Våre funn angående aldersforskjeller antyder at ulike aldersgrupper vil ha ulik nytte av forbedringer i de psykiske helsetjenestene og behandlingsmåtene. Men vi kan ikke si om dette skyldes seleksjonseffekter eller har andre grunner. For eksempel kan det begrensede antallet sykehussenger gjøre at flere yngre nye pasienter får sykehusbehandling med den følge at bare ekstremt syke eldre pasienter får bli innlagt. Det kan også være aldersforskjeller for eksempel når det gjelder motivasjonen for å søke psykiatrisk rådgivning, holdninger til antidepressiva, så vel som preferanser for å velge nye generasjoner antidepressive medikamenter.

\section{Oppsummering}

Vi har gjort en serie studier av utviklingen av psykiatrisk sykehusbehandling i et land der alle borgere har lik tilgang til gratis innleggelse og behandling. Dette har gitt oss mulighet til å oppnå presis og kumulativ informasjon om personer med en historie med sykehusinnleggelser for psykiske lidelser, og våre data er basert på et materiale der det uansett sosioøkonomisk status ikke er skjevheter i tilgang på tjenester fra psykisk helsevern. Selv om man bør være forsiktig med å generalisere forskningsfunn, vil våre funn være anvendbare i land med en tilsvarende sosial organisering, slik som Norge og tilsvarende land.

Vi vil hevde at våre studier har gitt et substansielt bidrag til kunnskapen om selvmordsrisiko i relasjon til det å ha vært sykehusinnlagt for psykiske lidelser, og om endringene i slik selvmordsrisiko i løpet av de siste 20 årene. Disse funnene kan være til hjelp når helsearbeidere skal legge strategier for å redusere antallet selvmord i denne høyrisikogruppen.

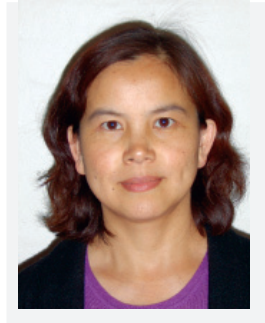

Ping Qin er førsteamanuensis i psykiatrisk epidemiologi ved Det nasjonale senter for registerbasert forskning ved Arhus universitet i Danmark. Hennes fremragende forskning, spesielt innen suicidologi, har resultert i mer enn 30 publikasjoner i prestisjefylte internasjonale forskningstidsskrifter. Hun har vært styremedlem $\mathrm{i}$ Dansk forening for selvmordsforskning og -forebygging siden stiftelsen i 2004 .

(Artikkelen er oversatt av Henning Herrestad.)

\section{Referanser}

Bramness, J. G., Walby, F. A., \& Tverdal, A. (2007). The sales of antidepressants and suicide rates in Norway and its counties 1980-2004. J.Affect.Disord., 102, $1-9$.

Gunnell, D., Saperia, J., \& Ashby, D. (2005). Selective serotonin reuptake inhibitors (SSRIs) and suicide in adults: meta-analysis of drug company data from placebo controlled, randomised controlled trials submitted to the MHRA's safety review. BMJ, 330 (7488), 385.

Harris, E. C. \& Barraclough, B. (1997). Suicide as an outcome for mental disorders. A meta-analysis. Br J Psychiatry, 170, 205-228.

Isacsson, G., Holmgren, P., \& Ahlner, J. (2005). Selective serotonin reuptake inhibitor antidepressants and the risk of suicide: a controlled forensic database study of 14857 suicides. Acta Psychiatr.Scand., 111, 286-290. Lægemiddelstyrelsen. (1999). Lægemiddelstatistik 1994-1998. Albertslund, Danmark: Schultz Information. Lægemiddelstyrelsen. (2003). Lægemiddelstatistik 1998-2002. Albertslund, Danmark: Schultz Information. Mortensen, P. B., Agerbo, E., Erikson, T., Qin, P., \& Westergaard-Nielsen, N. (2000). Psychiatric illness and risk factors for suicide in Denmark. Lancet, 355, 9-12. Qin, P., Agerbo, E., \& Mortensen, P. B. (2003). Suicide risk in relation to socioeconomic, demographic, psychiatric, and familial factors: a national register-based study of all suicides in Denmark, 1981-1997. Am.J Psychiatry, 160, 765-772.

Qin, P. \& Nordentoft, M. (2005). Suicide risk in relation to psychiatric hospitalization: evidence based on longitudinal registers. Arch. Gen.Psychi-atry, 62, 427-432. Qin, P., Nordentoft, M., Hoyer, E. H., Agerbo, E., Laursen, T. M., \& Mortensen, P. B. (2006). Trends in suicide risk associated with hospitalized psychiatric illness: a case-control study based on Danish longitudinal registers. J.Clin.Psychiatry., 67, 1936-1941.

Rihmer, Z. (2007). Suicide risk in mood disorders. Curr.Opin.Psychiatry., 20, 17-22.

Saha, S., Chant, D., \& McGrath, J. (2007). A systematic review of mortality in schizophrenia: is the differential mortality gap worsening over time? Arch.Gen.Psychiatry., 64, 1123-1131.

Socialministeriet og Sundhedsministeriet (2002). Government report on services for the mentally ill 2000. København: Statens Information.

Sundhedsstyrelsen (1998). Bilagsdel til Forslag til handlingsplan til forebyggelse af selvmordsfors $\phi g$ og selvmord i Danmark. København. 